\title{
Acute chest syndrome shows a predilection for basal lung regions on the side of upper abdominal surgery
}

\author{
[Le syndrome pulmonaire aigu montre une prédilection pour les régions basales du \\ poumon du côté de la chirurgie abdominale baute]
}

Mark W. Crawford mbbs FrCPC, Melanie Speakman MBChb MRCP FRCA, Edmund D. Carver mbBS MrCP FRCA, Peter C. W. Kim MD PhD FRCSC

\begin{abstract}
Purpose: Upper abdominal surgery for cholecystectomy or splenectomy is the most frequently performed surgical procedure in patients with sickle cell disease (SCD). The acute chest syndrome (ACS) is the most common sickle-related postoperative complication. The objective of the study was to characterize the clinical and radiological presentation of ACS complicating cholecystectomy and splenectomy.
\end{abstract}

Methods: The medical records of all children with SCD undergoing cholecystectomy or splenectomy during the 15-year period from January 1988 through December 2002 were reviewed. Patients who experienced ACS within 14 days after surgery were identified. Data collected included demographics, perioperative management, clinical and radiological findings, and outcome.

Results: The overall incidence of postoperative ACS was 16\%, occurring in nine of $5 \mathrm{I}$ patients having cholecystectomy and in seven of 48 patients having splenectomy. Mean time to onset of symptoms was $49 \mathrm{hr}$ after surgery (range, 24-96 hr). Cough, fever, and an abnormal chest examination were documented for all patients at presentation. Radiologically, ACS involved the basal lobes in all cases and was multi-lobar in $25 \%$. Patients were more likely to have new infiltrates involving the lung on the side of the surgery or bilateral infiltrates than isolated contralateral infiltrates at presentation $(P<0.000 \mathrm{I})$. Isolated upper or middle lobe involvement did not occur. Fifty percent of cases demonstrated evidence of a pleural effusion.

Conclusion: ACS complicating cholecystectomy or splenectomy shows a predilection for basal lung regions and for the lung on the side of surgery. These results have implications for the pathogenesis and prevention of postoperative ACS.
Objectif : L'intervention chirurgicale abdominale haute pour une cholécystectomie ou une splénectomie est l'opération la plus fréquente chez les patients atteints de drépanocytose. Le syndrome pulmonaire aigu (SPA) est la complication postopératoire la plus fréquente reliée à la drépanocytose. Nous voulions montrer la présentation clinique et radiologique du SPA suivant la cholécystectomie et la splénectomie.

Méthode : Les dossiers médicaux de tous les enfants atteints de drépanocytose, qui ont subi une cholécystectomie ou une splénectomie entre janvier 1988 et décembre 2002, ont été revus. Les patients atteints d'un SPA pendant les 14 jours suivant l'opération ont été repérés. Nous avons noté les caractéristiques démographiques, la prise en charge périopératoire, les constatations cliniques et radiologiques et les conséquences opératoires.

Résultats : L'incidence totale de SPA postopératoire a été de $16 \%$, survenant chez 9 des 51 patients avec cholécystectomie et chez 7 patients avec splénectomie. L'apparition des symptômes a pris en moyenne 49 h après l'opération (étendue, 24 - 96 h). La toux, la fièvre et l'examen pulmonaire anormal ont été notés pour tous les patients examinés. Au plan radiologique, le SPA intéressait les lobes inférieurs dans tous les cas et était multilobaire dans $25 \%$ des cas. L'examen montrait plus de nouveaux infiltrats touchant le poumon du côté de l'opération ou des infiltrats bilatéraux que des infiltrats controlatéraux isolés $(P<0,0001)$. Une atteinte isolée du lobe supérieur ou moyen ne s'est pas présentée. Un épanchement pleural a été mis en évidence dans $50 \%$ des cas.

Conclusion : Le SPA compliquant une cholécystectomie ou une splénectomie montre une prédilection pour les régions pulmonaires basses et pour le poumon du côté opéré. Ces résultats ont des implications sur la pathogenèse et la prévention du SPA postopératoire.

From the Departments of Anesthesia and Surgery and the Research Institute, The Hospital for Sick Children, University of Toronto, Toronto, Ontario, Canada.

Address correspondence to: Dr. Mark Crawford, Department of Anesthesia, The Hospital for Sick Children, 555 University Avenue, Toronto, Ontario M5G 1X8, Canada. Phone: 416-813-6466; Fax: 416-813-7543; E-mail: mark.crawford@sickkids.ca

Support was provided from departmental sources.

Assessed October 15, 2003

Revision accepted March 1, 2004.

CAN J ANESTH 2004/51:7/pp 707-711 


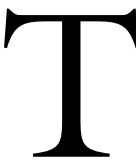

HE acute chest syndrome (ACS) is the most common postoperative complication and the leading cause of death resulting from sickle cell disease (SCD). ${ }^{1-4}$ Defined as a new pulmonary infiltrate that involves at least one complete lung segment in association with fever and respiratory symptoms, ACS occurs spontaneously or as a postoperative complication in more than $50 \%$ of children diagnosed with SCD. ${ }^{3-6}$ The exact cause of ACS is uncertain in most cases. ${ }^{7}$

As a consequence of hemolysis and sequestration, abdominal surgery for cholecystectomy and splenectomy is the most frequently performed surgical procedure in patients with SCD. ${ }^{3,4}$ These operations are associated with a relatively high incidence of postoperative ACS. ${ }^{3,4,8}$ In a retrospective study from this institution, ACS complicating cholecystectomy and splenectomy was characterized by new pulmonary infiltrates that occurred predominantly on the side of the abdominal surgery. ${ }^{8}$ However, the number of episodes of ACS was inadequate to establish a statistically significant relationship between pulmonary infiltrates and operative site. To further characterize the clinical and radiological presentation of postoperative ACS in children, we reviewed all cases of postoperative ACS complicating cholecystectomy or splenectomy at our institution during the 15-year period extruding from January 1988 through December 2002.

\section{Methods}

With Research Ethics Board approval, we conducted a retrospective analysis of the medical records and chest radiographs of all children who experienced ACS after undergoing cholecystectomy or splenectomy during the 15-year period from January 1988 through December 2002. The Hospital for Sick Children Health Records Clinical Database was used to identify potential cases. For the period January 1988 to March 2002, the hospital database was created by coding and classifying all diagnoses and procedures documented in the medical record using the International Classification of Diseases, 9th Revision, Clinical Modification (ICD-9-CM). Thereafter, the 10th Revision (ICD-10-CA) was used to create the database. Patients diagnosed with SCD who underwent cholecystectomy or splenectomy in the 15-year period were identified using the following ICD-9-CM codes: $282.60,282.69,51.22,51.23,41.50$, and 41.43; and the following ICD-10-CA codes: D570, D571, D572, 1.OD.98, 1.OB.89, and 1.OB.87. The medical records were subsequently reviewed to identify patients who experienced ACS within 14 days after surgery. All children diagnosed with postoperative
ACS were included in the analysis. The diagnosis of ACS was based on the following criteria: 1) radiographic evidence of a new pulmonary infiltrate that involved at least one complete lung segment and was consistent with the presence of alveolar consolidation, but excluding atelectasis; 2) a temperature greater than $38.0^{\circ} \mathrm{C}$; and 3 ) respiratory symptoms. ${ }^{4,9,10}$ Specific data collected for each patient included demographics, perioperative management, clinical and radiological presentation, and outcome. Fisher's exact test was used for comparison of categorical variables, and Student's t test for continuous outcomes. Data are presented as mean \pm SD. $P<0.05$ was considered statistically significant.

\section{Results}

\section{Patient characteristics}

Ninety-nine patients diagnosed with SCD underwent cholecystectomy or splenectomy during the 15-year study period. The overall incidence of postoperative ACS was $16 \%$, occurring in nine of 51 patients following cholecystectomy and in seven of 48 patients following splenectomy. The mean age and weight of the 16 patients were $9.4 \mathrm{yr}$ (range, 3.9-18 yr) and $30 \mathrm{~kg}$ (range, 13-56 kg), respectively. Eleven (69\%) were female. Ten $(63 \%)$ had homozygous hemoglobin S disease (SS), four (25\%) had sickle-hemoglobin C disease (SC), and two (13\%) had sickle- $\beta$-thalassemia. Eleven $(69 \%)$ had a history of a previous spontaneous ACS.

\section{Perioperative management}

Preoperatively, the mean hemoglobin concentration was $94.5 \pm 11.1 \mathrm{~g} \cdot \mathrm{L}^{-1}$ (range, $76.0-121 \mathrm{~g} \cdot \mathrm{L}^{-1}$ ). Overnight preoperative hydration using 1.0 to 1.5 times the maintenance rate was documented for seven (44\%) patients, and preoperative simple transfusion for four $(25 \%)$. Intraoperative management consisted of general anesthesia with preoxygenation, tracheal intubation, positive pressure ventilation, and temperature conservation techniques in all patients. No regional anesthesia was performed. Nine patients $(56 \%)$ had laparoscopic surgery. Three laparoscopic procedures were converted to open surgery. Total anesthesia time (the time from induction to emergence from anesthesia) was significantly less for cholecystectomy (mean duration, $118 \mathrm{~min}$; range, $75-165 \mathrm{~min})$ than for splenectomy (mean duration, 214 min; range, 80-380 min; $P<0.01)$. There were no documented episodes of intraoperative oxygen desaturation, hypotension, or blood loss requiring administration of blood products. All patients received supplemental oxygen in the postoperative care unit. Analgesia was provided with continuous morphine infusion in $56 \%$, patient controlled 
analgesia (PCA) using morphine in $38 \%$, or intermittent $i v$ opioid boluses in $13 \%$. The prophylactic use of postoperative incentive spirometry was not documented for any patient.

\section{Clinical presentation of postoperative ACS}

The most common presenting symptoms were cough and fever, which were present in all patients. Chest pain was less common, occurring in 38\%. Tachypnea, tachycardia, and an abnormal chest examination were documented for all patients. Findings on chest examination included decreased breath sounds in all patients, crepitations in $75 \%$, the use of accessory muscles of respiration in $57 \%$, bronchial breathing in $31 \%$, and wheezing in $6 \%$. The overall mean time to onset of symptoms was $49 \pm 20 \mathrm{hr}$ after the end of surgery (range, 24-96 hr). Time to onset of symptoms in patients with bilateral chest infiltrates at presentation ( $65 \pm 17 \mathrm{hr}$; range, $48-96 \mathrm{hr}$ ) was significantly greater than in those with unilateral infiltrates $(39 \pm 15 \mathrm{hr}$; range $24-72 \mathrm{hr} ; P<0.01)$. Hemoglobin oxygen saturation decreased from a mean of $97 \%$ in the immediate postoperative period to $87 \%$ (range, $70 \%-95 \%$ ) with the onset of ACS despite administration of supplemental oxygen $(P<0.05)$.

\section{Radiological findings}

Five of the nine patients who developed ACS after cholecystectomy had new pulmonary infiltrates involving the right lung and four had bilateral infiltrates at presentation. Five of the seven patients who developed ACS after splenectomy had new pulmonary infiltrates in the left lung and two had bilateral infiltrates. In no patient was ACS isolated to the lung opposite the operative site. Patients were more likely to present with pulmonary infiltrates on the side of surgery or bilateral pulmonary infiltrates than with isolated contralateral involvement $(P<0.0001)$. ACS involved the basal lobes in all cases and was multi-lobar in $25 \%$ of cases. Isolated upper or middle lobe disease did not occur in any patient. Six of the ten patients who had unilateral disease at presentation progressed radiologically to bilateral involvement within $48 \mathrm{hr}$. Fifty percent of all cases had evidence of a pleural effusion on the chest radiograph. Chest radiographs repeated at the time of discharge from hospital in all but two children demonstrated partial resolution of the pulmonary infiltrates in ten and no change in four.

\section{Therapy and hospital course}

Therapy for ACS included the administration of supplemental oxygen, iv antibiotics, opioid analgesics, chest physiotherapy, and incentive spirometry in all cases. The onset of ACS was associated with a reduction in hemoglobin concentration (mean reduction, $\left.15.1 \pm 8.9 \mathrm{~g} \cdot \mathrm{L}^{-1} ; P<0.05\right)$, which was treated with simple transfusion in two patients and exchange transfusion in one. The duration of oxygen therapy was 5 \pm 1 days. One patient with unilateral involvement who was transfused preoperatively required nasal bi-level positive airway pressure for $48 \mathrm{hr}$ in the intensive care unit. The overall mean length of postoperative hospitalization was nine days (range, 5-13 days). No positive sputum, blood or urine cultures were documented. There were no vaso-occlusive pain crises or other postoperative complications of SCD and no deaths attributed to ACS.

\section{Discussion}

The overall incidence of postoperative ACS in this retrospective study was $16 \%$, which is similar to previously reported rates for sickle-related complications after abdominal or thoracic surgery, $15 \%$ to $19 \% ., 11,12$ Postoperative ACS was characterized by predominantly basal pulmonary infiltrates that always involved the lung on the side of the surgery and either remained localized to that lung or progressed to involve both lungs. Isolated upper or middle lobe infiltrates or isolated contralateral infiltrates did not occur in any patient. In addition, ACS was associated with radiographic evidence of a pleural effusion in $50 \%$ of children. These features of postoperative ACS are in contrast to those reported for children presenting with spontaneous ACS. ${ }^{6}$ In the case of spontaneous ACS, children are prone to have isolated upper or middle lobe involvement and the incidence of pleural effusion is much less than that observed in the present study, $3 \%{ }^{6}$ Thus, postoperative ACS appears to differ in some aspects from spontaneous ACS in children. Although the current study was not designed to investigate the pathogenesis of postoperative ACS in children, these observations might provide some insight.

Postoperative ACS showed a predilection for basal lung regions and for the lung on the side of the abdominal surgery. Increasing evidence indicates that hypoxia plays a cardinal role in the pathophysiology of ACS. ${ }^{13-15}$ Upper abdominal surgery, whether performed via laparotomy or laparoscopy, is associated with significant basal pulmonary atelectasis and hypoxemia, resulting in part from factors such as positive pressure ventilation, pneumoperitoneum, lung compression from surgical retractors, altered chest wall and diaphragmatic mechanics, and hypoventilation in the postoperative period due to pain or narcotics. ${ }^{16-21}$ Atelectasis causes intrapulmonary shunting, ${ }^{22}$ and the regional hypoxia that ensues could 
potentially enhance hemoglobin $S$ polymerization, upregulate endothelial cell adhesion receptors, and thereby contribute to the intrapulmonary sequestration of erythrocytes and vaso-occlusion known to occur in ACS. ${ }^{1,13}$ Strategies such as alveolar recruitment maneuvers and incentive spirometry have been shown to decrease the frequency of postoperative atelectasis and pulmonary complications. ${ }^{20,23}$ Moreover, the early prophylactic use of incentive spirometry every two hours during the day and while awake at night significantly decreased the incidence of ACS in SCD patients admitted to hospital for acute pain. ${ }^{24}$ By preventing pulmonary atelectasis, it is plausible that these strategies could also avert postoperative ACS or decrease its severity.

Additionally, our finding that involvement of the ipsilateral lung predominates at presentation suggests that a local inflammatory response to surgery might be involved. The magnitude of the local inflammatory response evoked by open and laparoscopic cholecystectomy is similar, as demonstrated by similar increases in immunohistochemically detected peritoneal inflammatory cytokines. ${ }^{25}$ Like hypoxia, inflammatory cytokines cause sickle cells to adhere to the pulmonary endothelium by upregulating endothelial cell adhesion receptors. ${ }^{15}$ Cytokines also play a pivotal role in inflammatory reactions within the lung. ${ }^{26}$ The anti-inflammatory action of glucocorticoids has been shown to have a beneficial effect in children with ACS or vaso-occlusive crises. ${ }^{9,27}$ In a double-blind placebo-controlled trial, dexamethasone significantly shortened the duration of symptomatic spontaneous ACS and hastened discharge from hospital. ${ }^{9}$ However, the safety and efficacy of antiinflammatory drugs as a prophylaxis for postoperative ACS has not been investigated.

In the current study, two-thirds of patients in whom ACS developed had a history of previous spontaneous ACS and two-thirds were homozygous for the SS genotype. Other known risk factors for $\mathrm{ACS}^{1}$ such as a low fetal hemoglobin concentration and high steady state neutrophil count were not documented for any patient. The onset of postoperative ACS was associated with significant hypoxemia and a reduction in hemoglobin concentration below steady state values, as previously reported. ${ }^{6}$ Postulated etiologic factors ${ }^{7,9,28}$ such as infection and pulmonary fat embolism from infarcted bone marrow were not identified. Although ACS is frequently self-limiting in children, it can rapidly progress to respiratory failure, cardiovascular collapse, encephalopathy, multi-organ failure, rhabdomyolysis and sudden death. ${ }^{28}$ Recurrent episodes lead to pulmonary hypertension, chronic restrictive lung disease, and cor pulmonale, ${ }^{1,5,23,28}$ emphasizing that aggressive prevention of this complication in the postoperative period is prudent.

In the current study, $25 \%$ of patients in whom ACS developed had received simple preoperative transfusion. Even with exchange transfusion there was a morbidity rate of $14 \%$ among SCD patients having cholecystectomy. ${ }^{29}$ In a randomized trial, Vichinsky et al. reported that simple transfusion was as effective as exchange transfusion (to decrease $\mathrm{HbS}$ to less than $30 \%$ ) in preventing sickle-related postoperative complications and was associated with $50 \%$ fewer transfusion-related complications. ${ }^{4}$ In a subset of non-randomized patients having cholecystectomy without preoperative transfusion, the incidence of postoperative sickle-related complications was as high as $38 \%{ }^{12}$ Similarly, in the Cooperative Study of Sickle Cell Disease, the risk of postoperative ACS increased as the total hemoglobin concentration decreased in patients undergoing abdominal surgery. ${ }^{3}$ However, the lack of prospective data from a rigorous randomized controlled trial makes recommendations regarding preoperative transfusion difficult.

Clinically, it can be difficult or nearly impossible to distinguish ACS from uncomplicated pneumonia and other causes of a new pulmonary infiltrate in the postoperative period. Moreover, we cannot exclude the possibility that some children who were mildly symptomatic might not have received a postoperative chest radiograph, and hence episodes of mild severity could have been missed clinically. ${ }^{30}$ Thus it is important that care be exercised in generalizing the results of the current retrospective analysis.

In conclusion, ACS remains a common and potentially serious complication of abdominal surgery in children diagnosed with SCD. The predominance of lower lobe involvement may be attributable to atelectasis and hypoxia. The predilection for involvement of the lung on the side of the surgery suggests that a local inflammatory response to surgery might also play a role in the pathogenesis of postoperative ACS. Based on these observations, we recommend the routine use of strategies such as intraoperative alveolar recruitment maneuvers, postoperative incentive spirometry, and judicious postoperative analgesia to prevent pulmonary atelectasis after upper abdominal surgery in patients with SCD. Additionally, the role of preoperative transfusion, anti-inflammatory drugs, and neuraxial analgesia needs further investigation. Prospective controlled studies are warranted to evaluate the safety and efficacy of these interventions as a prophylaxis for ACS in this patient population. 


\section{References}

1 Platt OS, Brambilla DJ, Rosse WF, et al. Mortality in sickle cell disease. Life expectancy and risk factors for early death. N Engl J Med 1994; 330: 1639-44.

2 Vichinsky EP, Styles LA, Colangelo LH, Wright EC, Castro $O$, Nickerson B. Acute chest syndrome in sickle cell disease: clinical presentation and course. Blood 1997; 89: 1787-92.

3 Koshy M, Weiner SJ, Miller ST, et al. Surgery and anesthesia in sickle cell disease. Blood 1995; 86: 3676-84.

4 Vichinsky EP, Haberkern CM, Neumayr L, et al. A comparison of conservative and aggressive transfusion regimens in the perioperative management of sickle cell disease. N Engl J Med 1995; 333: 206-13.

5 Castro O, Brambilla DJ, Thorington B, et al. The acute chest syndrome in sickle cell disease: incidence and risk factors. Blood 1994; 84: 643-9.

6 Gill FM, Sleeper LA, Weiner SJ, et al. Clinical events in the first decade in a cohort of infants with sickle cell disease. Blood 1995; 86: 776-83.

7 Weil JV, Castro O, Malik AB, Rodgers G, Bonds DR, Jacobs TP. Pathogenesis of lung disease in sickle hemoglobinopathies. Am Rev Respir Dis 1993; 148: 249-56.

8 Wales PW, Carver E, Crawford MW, Kim PC. Acute chest syndrome after abdominal surgery in children with sickle cell disease: is a laparoscopic approach better? J Pediatr Surg 2001; 36: 718-21.

9 Bernini JC, Rogers ZR, Sandler ES, Reisch JS, Quinn $C T$, Buchanan GR. Beneficial effect of intravenous dexamethasone in children with mild to moderately severe acute chest syndrome complicating sickle cell disease. Blood 1998; 92: 3082-9.

10 Delatte SJ, Hebra A, Tagge EP, Jackson S, Jacques K, Biemann Othersen H Jr. Acute chest syndrome in the postoperative sickle cell patient. J Pediatr Surg 1999; 34: 188-92.

11 Griffin TC, Buchanan GR. Elective surgery in children with sickle cell disease without preoperative blood transfusion. J Pediatr Surg 1993; 28: 681-5.

12 Haberkern CM, Neumayr LD, Orringer EP, et al. Cholecystectomy in sickle cell anemia patients: perioperative outcome of 364 cases from the National Preoperative Transfusion study. Blood 1997; 89: 1533-42.

13 Stuart MJ, Setty BN. Acute chest syndrome of sickle cell disease: new light on an old problem. Curr Opin Hematol 2001; 8: 111-22.

14 Setty BN, Stuart MJ. Vascular cell adhesion molecule-1 is involved in mediating hypoxia-induced sickle red blood cell adherence to endothelium: potential role in sickle cell disease. Blood 1996; 88: 2311-20.

15 Stuart MJ, Setty BN. Sickle cell acute chest syndrome: pathogenesis and rationale for treatment. Blood 1999; 94: 1555-60.
16 Craig $D B$. Postoperative recovery of pulmonary function. Anesth Analg 1981; 60: 45-52.

17 Schawer PR, Luna J, Ghiatas AA, Glen ME, Warren $J M$, Sirinek KR. Pulmonary function after laparoscopic cholecystectomy. Surgery 1993; 114: 389-99.

18 Froese $A B$, Bryan AC. Effects of anesthesia and paralysis on diaphragmatic mechanics in man. Anesthesiology 1974; 41: 242-55.

19 Rehder K, Mallow JE, Fibuch EE, Krabill DR, Sessler $A D$. Effects of isoflurane anesthesia and muscle paralysis on respiratory mechanics in normal man. Anesthesiology 1974; 41: 477-85.

20 Tusman G, Böhm SH, Tempra A, et al. Effects of recruitment maneuver on atelectasis in anesthetized children. Anesthesiology 2003; 98: 14-22.

21 Andersson L, Bååth M, Thörne A, Odeberg-Wernerman $S$. Effect of $\mathrm{CO}_{2}$ pneumoperitoneum on atelectasis development during anesthesia. Anesthesiology 2002; Al335 (abstract).

22 Tokics L, Hedenstierna G, Stradberg A, Brismar B, Lundquist $H$. Lung collapse and gas exchange during general anesthesia: effects of spontaneous breathing, muscle paralysis, and positive end-expiratory pressure. Anesthesiology 1987; 66: 157-67.

23 Krastins IR, Corey ML, McLeod A, Edmonds J, Levison H, Moes F. An evaluation of incentive spirometry in the management of pulmonary complications after cardiac surgery in a pediatric population. Crit Care Med 1982; 10: 525-8.

24 Bellet PS, Kalinyak KA, Shukla R, Gelfand MJ, Rucknagel $D L$. Incentive spirometry to prevent acute pulmonary complications in sickle cell diseases. N Engl J Med 1995; 333: 699-703.

25 Sendt W, Amberg R, Schoffel U, Hassan A, von Specht $B U$, Farthmann EH. Local inflammatory peritoneal response to operative trauma: studies on cell activity, cytokine expression, and adhesion molecules. Eur J Surg 1999; 165: 1024-30.

26 Luster AD. Chemokines-chemotactic cytokines that mediate inflammation. N Engl J Med 1998; 338: 436-45.

27 Griffin TC, McIntire D, Buchanan GR. High-dose intravenous methylprednisolone therapy for pain in children and adolescents with sickle cell disease. N Engl J Med 1994; 330: 733-7.

28 Vichinsky EP, Neumayr LD, Earles AN, et al. Causes and outcomes of the acute chest syndrome in sickle cell disease. N Engl J Med 2000; 342: 1855-65.

29 Rudolph R, Williams JS. Cholecystectomy in patients with sickle cell disease: experience at a regional hospital in southeast Georgia. J Natl Med Assoc 1992; 84: 692-6.

30 Morris C, Vichinsky E, Styles L. Clinician assessment for acute chest syndrome in febrile patients with sickle cell disease: is it accurate enough? Ann Emerg Med 1999; 34: 64-9. 